\title{
Editorial \\ Special Issue on New Carbon Materials from Biomass and Their Applications
}

\author{
Jorge Bedia *(1) and Carolina Belver *(1) \\ Departamento de Ingeniería Química, Universidad Autónoma de Madrid, Cantoblanco, 28049 Madrid, Spain \\ * Correspondence: jorge.bedia@uam.es (J.B.); carolina.belver@uam.es (C.B.)
}

Citation: Bedia, J.; Belver, C. Special Issue on New Carbon Materials from Biomass and Their Applications.

Appl. Sci. 2021, 11, 2453.

https://doi.org/10.3390/app11062453

Received: 19 February 2021

Accepted: 4 March 2021

Published: 10 March 2021

Publisher's Note: MDPI stays neutral with regard to jurisdictional claims in published maps and institutional affiliations.

Copyright: (c) 2021 by the authors. Licensee MDPI, Basel, Switzerland. This article is an open access article distributed under the terms and conditions of the Creative Commons Attribution (CC BY) license (https:// creativecommons.org/licenses/by/ $4.0 /)$.

\section{Introduction}

Carbon-based materials, such as chars, activated carbons, one-dimensional carbon nanotubes, and two-dimensional graphene nanosheets, have shown great potential for a wide variety of applications. These materials can be synthesized from any precursor with a high proportion of carbon in its composition. Although fossil fuels have been extensively used as precursors, their unstable cost and supply have led to the synthesis of carbon materials from biomass [1]. More importantly, pollution and $\mathrm{CO}_{2}$ emissions and their impact on climate change are real issues that should concern the scientific community now and lead to the replacement of fossil resources with more environmentally friendly sources. Biomass covers all forms of organic material, including plants, both living and in waste form, and animal waste products. To take full advantage of the renewable characteristics of biomass waste, it should be processed through sustainable processes following the green chemistry principles, such as low energy consumption, high atom efficiency, or use of less hazardous chemicals, among others. The applications of these biomass-derived carbon materials include electronic, electromagnetic, electrochemical, environmental, and biomedical applications. Thus, novel carbon materials from biomass are a subject of intense research, with strong relevance to both science and technology.

\section{New Carbon Materials from Biomass and Their Applications}

This special issue includes relevant works about the synthesis of carbon-based materials from biomass waste and their use in different applications, with special attention to biochar. In this sense, Ferrentino et al. [2] synthesized several hydrochars from municipal sewage sludge that showed high adsorption capacities of methylene blue dye. A subsequent $\mathrm{KOH}$ treatment enhanced adsorption capacity, which seems to be controlled by a complex result of various phenomena, including physi- and chemisorption and acid-base and redox equilibria. The adsorption of this same dye was analyzed by Li et al. [3], who used Artemisia selengensis to produce biochar by microwave pyrolysis. The results indicated that the increase of the pyrolysis temperature results in a decrease of the yield but an increase of the dye adsorption. The use of biochars as adsorbents for water purification was also analyzed by Siipola et al. [4]. In this case, the biochars from pine and spruce bark were subsequently activated with steam at $800{ }^{\circ} \mathrm{C}$ and studied in the removal of phenol, and microplastics retention and cation exchange capacity were employed as key test parameters. The work concluded that ultra-high porosities are not necessary for satisfactory water purification, supporting the economic feasibility of bio-based adsorbent production. Similarly, Diaz et al. [5] reported the preparation of low-cost activated grape seed-derived hydrochar through hydrothermal carbonization and chemical activation with different chemical activating agents $\left(\mathrm{KOH}, \mathrm{FeCl}_{3}\right.$, and $\left.\mathrm{H}_{3} \mathrm{PO}_{4}\right)$ for sulfamethoxazole adsorption. The hydrochars showed low porosity, however their activation with $\mathrm{KOH}$ resulted in highly porous activated carbons $\left(2200 \mathrm{~m}^{2} \cdot \mathrm{g}^{-1}\right)$. The adsorption capacity was determined by the porous texture, achieving a high saturation capacity of $650 \mathrm{mg} \cdot \mathrm{g}^{-1}$. Tuomikoski et al. [6] detailed the zinc adsorption using activated carbon prepared from sawdust waste. 
Carbonization and activation were performed in a single stage using steam as a physical activation agent at $800{ }^{\circ} \mathrm{C}$. The adsorption capacity towards zinc was tested and compared favorably to those of the materials reported in the literature. Not only liquid-phase but also gas-phase adsorption applications are included in this special issue. Manyà et al. [7] analyzed the dynamic $\mathrm{CO}_{2}$ capture on physically activated biochars. Those were obtained from vine shoots and wheat straw pellets through an initial slow pyrolysis and further activation with $\mathrm{CO}_{2}$ up to different degrees of burn-off. The adsorbent prepared from the vine shoots-derived biochar with the most hierarchical pore size distribution exhibited a good and stable performance under dry conditions. However, the presence of relatively high concentrations of water vapor in the feeding gas clearly interfered with the $\mathrm{CO}_{2}$ adsorption mechanism, leading to significantly shorter breakthrough times.

Besides biochar, many of the publications collected in this special issue were devoted to soil enrichment. Yu et al. [8] reported the use of mixed hardwood and sugarcane bagasse biochar as potting mix components for container tomato and basil seedling production. The study concluded that $70 \%$ mixed hardwood biochar could be amended with peat moss for tomato and basil seedling production without negative effects on plant biomass. Similarly, Saletnik et al. [9] investigated the stimulation and conditioning of seeds with biochar and the effects observed in the germination and emergence of Virginia mallow seedlings. The biochars, applied as conditioner added to water in the process of seed hydration, improved the germination capacity. The beneficial effects of biochar application were also reflected in the increased mass of Virginia mallow seedlings. Shin el al. [10] used nutrient uploaded biochar pellets as slow release fertilizers. It was observed that the cumulative ammonium nitrogen in the blended biochar pellets was slow released over the 77 days of precipitation period, but nitrite nitrogen was rapidly released, i.e., within 15 days of precipitation. Accumulated phosphate phosphorus concentrations were not much different, and slowly released until the final precipitation period. These findings indicated that blended biochar pellets can be used as slow-release fertilizers for agricultural practices. The effect of biochar application depth on crop productivity under tropical rainfed conditions was researched by Moiwo et al. [11]. The study determined the effect of biochar application depth on the productivity of NERICA-4 upland rice cultivars under tropical rainfed conditions, concluding that the biochar can enhance crop productivity. Finally, Huang et al. [12] evaluated the use of biochar and compost mixes as substitutes to a commercial propagation mix. High percentages ( $70 \%$ or $80 \%$, by volume) of biochars with vermicompost or chicken manure compost were evaluated to substitute a commercial propagation mix. The combination of biochars with vermicompost improves the results, however the mixture with chicken manure compost was not recommended.

The use of biomass waste as a potential environmentally friendly energy source is also a relevant research field. In this sense, Mousa et al. [13] studied the use of biocarbon briquettes for foundry industry. The foundry industry, like many others, is currently facing challenges to reduce the environmental impacts from application of fossil fuels. Replacing foundry coke with alternative renewable carbon sources can lead to significant decreases in fossil fuel consumption and fossil $\mathrm{CO}_{2}$ emission. The work was aimed at the design, optimization, and development of briquettes containing biocarbon for an efficient use in cupola furnace.

Biomass-derived carbons are also being extensively analyzed as part of catalysts and /or catalyst's support in different catalytic reactions. Lu et al. [14] synthesized solid acid catalysts by one-step carbonization and sulfonation of Salix psammophila in the presence of concentrated sulfuric acid. The catalysts were used in the esterification reaction between oleic acid and methanol to prepare the biodiesel, achieving a conversion of $94.15 \%$ in the optimized conditions. Ma et al. [15] reports the process simulation and economic evaluation of a two-stage bio-oil hydrogenation process. An Aspen Plus process simulation model was developed for the two-stage bio-oil hydrogenation demonstration plant, which was used to evaluate the effect of catalyst coking on the bio-oil upgrading process and the 
economic performance of the process. The model was also used to investigate the effect of catalyst deactivation caused by coke deposition in the mild stage.

Finally, we would like to mention two review contributions. The first one by Yang et al. [16] reviewed the preparation and modification of biochar materials and their application in soil remediation, which was extensively treated in this special issue. The wide application of biochar is due to its abilities to remove pollutants, remediate contaminated soil, and reduce greenhouse gas emissions. The study analyzed the influence of preparation methods, process parameters, and modification methods on the physicochemical properties of biochar, as well as the mechanisms of biochar in the remediation of soil pollution. The biochar applications in soil remediation in the past years were summarized, such as the removal of heavy metals and persistent organic pollutants (POPs), and the improvement of soil quality. The review also details the potential risks of biochar applications and the future research directions. The second review by Saletnik et al. [17] reported the use of biochar for environmental applications. The article reviews the information related to the broad uses of carbonization products. It also discusses the legal aspects and quality standards applicable to these materials, with special attention to the lack of uniform legal and quality conditions, which would allow for much better use of biochar. The review also aims to highlight the high potential for use of biochar in different environments. The presented text attempts to emphasize the importance of biochar as an alternative to classic products used for energy, for environmental and agricultural purposes.

Funding: This research received no external funding.

Institutional Review Board Statement: Not applicable.

Informed Consent Statement: Not applicable.

Data Availability Statement: Not applicable.

Acknowledgments: We would like to thank the authors, reviewers, and the editorial team of Applied Sciences for the work devoted to this special issue. We would like also to thank Tamia Qing for all her help advising and invaluable work during all the process.

Conflicts of Interest: The authors declare no conflict of interest.

\section{References}

1. Bedia, J.; Peñas-Garzón, M.; Gómez-Avilés, A.; Rodriguez, J.; Belver, C. A Review on the Synthesis and Characterization of Biomass-Derived Carbons for Adsorption of Emerging Contaminants from Water. C 2018, 4, 63. [CrossRef]

2. Ferrentino, R.; Ceccato, R.; Marchetti, V.; Andreottola, G.; Fiori, L. Sewage Sludge Hydrochar: An Option for Removal of Methylene Blue from Wastewater. Appl. Sci. 2020, 10, 3445. [CrossRef]

3. Li, X.; Li, K.; Geng, C.; El Mashad, H.; Li, H.; Yin, W. Biochar from Microwave Pyrolysis of Artemisia Slengensis: Characterization and Methylene Blue Adsorption Capacity. Appl. Sci. 2019, 9, 1813. [CrossRef]

4. Siipola, V.; Pflugmacher, S.; Romar, H.; Wendling, L.; Koukkari, P. Low-Cost Biochar Adsorbents for Water Purification Including Microplastics Removal. Appl. Sci. 2020, 10, 788. [CrossRef]

5. Diaz, E.; Manzano, F.J.; Villamil, J.; Rodriguez, J.J.; Mohedano, A.F. Low-Cost Activated Grape Seed-Derived Hydrochar through Hydrothermal Carbonization and Chemical Activation for Sulfamethoxazole Adsorption. Appl. Sci. 2019, 9, 5127. [CrossRef]

6. Tuomikoski, S.; Kupila, R.; Romar, H.; Bergna, D.; Kangas, T.; Runtti, H.; Lassi, U. Lassi Zinc Adsorption by Activated Carbon Prepared from Lignocellulosic Waste Biomass. Appl. Sci. 2019, 9, 4583. [CrossRef]

7. Manyà, J.J.; García-Morcate, D.; González, B. Adsorption Performance of Physically Activated Biochars for Postcombustion $\mathrm{CO}_{2}$ Capture from Dry and Humid Flue Gas. Appl. Sci. 2020, 10, 376. [CrossRef]

8. Yu, P.; Li, Q.; Huang, L.; Niu, G.; Gu, M. Mixed Hardwood and Sugarcane Bagasse Biochar as Potting Mix Components for Container Tomato and Basil Seedling Production. Appl. Sci. 2019, 9, 4713. [CrossRef]

9. Saletnik, B.; Bajcar, M.; Zaguła, G.; Saletnik, A.; Tarapatskyy, M.; Puchalski, C. Biochar as a Stimulator for Germination Capacity in Seeds of Virginia Mallow (Sida hermaphrodita (L.) Rusby). Appl. Sci. 2019, 9, 3213. [CrossRef]

10. Shin, J.; Park, S.; Lee, S. Optimum Method Uploaded Nutrient Solution for Blended Biochar Pellet with Application of Nutrient Releasing Model as Slow Release Fertilizer. Appl. Sci. 2019, 9, 1899. [CrossRef]

11. Moiwo, J.P.; Wahab, A.; Kangoma, E.; Blango, M.M.; Ngegba, M.P.; Suluku, R. Effect of Biochar Application Depth on Crop Productivity Under Tropical Rainfed Conditions. Appl. Sci. 2019, 9, 2602. [CrossRef]

12. Huang, L.; Yu, P.; Gu, M. Evaluation of Biochar and Compost Mixes as Substitutes to a Commercial Propagation Mix. Appl. Sci. 2019, 9, 4394. [CrossRef] 
13. Mousa, E.; Kazemi, M.; Larsson, M.; Karlsson, G.; Persson, E. Potential for Developing Biocarbon Briquettes for Foundry Industry. Appl. Sci. 2019, 9, 5288. [CrossRef]

14. Lu, P.; Wang, K.; Gong, J. Optimization of Salix Carbonation Solid Acid Catalysts for One-Step Synthesis by Response Surface Method. Appl. Sci. 2019, 9, 1518. [CrossRef]

15. Ma, X.; Pang, S.; Zhang, R.; Xu, Q. Process Simulation and Economic Evaluation of Bio-Oil Two-Stage Hydrogenation Production. Appl. Sci. 2019, 9, 693. [CrossRef]

16. Yang, X.; Zhang, S.; Ju, M.; Liu, L. Preparation and Modification of Biochar Materials and their Application in Soil Remediation. Appl. Sci. 2019, 9, 1365. [CrossRef]

17. Saletnik, B.; Zaguła, G.; Bajcar, M.; Tarapatskyy, M.; Bobula, G.; Puchalski, C. Biochar as a Multifunctional Component of the Environment-A Review. Appl. Sci. 2019, 9, 1139. [CrossRef] 